\title{
Evaluation of Heterogeneity Impact on Hydraulic Fracturing Performance
}

\author{
Hadi Parvizi $^{\mathrm{a}}$, Sina Rezaei-Gomari ${ }^{\mathrm{a}^{*}}$, Farhad Nabhani $^{\mathrm{a}}$, Andrea Turner ${ }^{\mathrm{b}}$ \\ ${ }^{\text {a }}$ School of Science and Engineering, Teesside University, Middlesbrough, TS1 3BA, UK \\ ${ }^{\mathrm{b}}$ EON E\&P, 129 Wilton Road, London, SW1V 1JZ, UK
}

\begin{abstract}
Hydraulic fracturing operation in tight reservoirs increases the connectivity of the well to more reservoir layers and further regions, thus boosting the production. Heterogeneity influences the hydraulic fracturing performance; this is observed when comparing the performance of different fracced wells. Those that far outperform other fracced wells are generally connected to more permeable rock or natural fractures.
\end{abstract}

Modelling hydraulic fracturing net pressure provides hydraulic fracture dimensions and connectivity per fracture job. Moreover, well test interpretation can imply the active number of hydraulic fractures and an average estimation of their dimensions and connectivity after cleaning up and flowing the well. There is a technical gap in the integration of well test data with fraccing operational data for diagnosing and evaluating the hydraulic fracture performance. This paper introduces a novel approach to link the hydraulic fracturing modelling with well test interpretation. This method quantifies heterogeneity impact on hydraulic fracture performance through introducing a new parameter defined as Heterogeneity Impact Factor (HIF). The calculated HIF for the fracced wells varies between $74 \%$ (indicating that the well far outperformed the expected hydraulic fracture performance) to $-65 \%$ (dramatically underperformed well). The outcome of the proposed technique was validated by geological observations and was subsequently applied to the dynamic simulation model. The pressure prediction of the model was compared with the three-week annual shut-down; the build-up response

\footnotetext{
* Corresponding author. Tel.: +44 7847012063

E-mail address: s,rezaei-gomari@tees.ac.uk (Sina R. Gomari).
} 
and its derivative display an excellent match which provides evidence for the robustness of the dynamic model and the effectiveness of the proposed technique.

\section{Introduction}

Since its introduction in the late 1940s, hydraulic fracturing has been widely used in North America to achieve higher recovery from low permeability reservoirs and/or to bypass the formation damage around the wellbore (Economides, et al., 2002). In addition, successful applications of this technique have been reported in other locations including North Sea (Vos, et al., 2009), South America (Antoci and Anaya, 2001), Asia (Shaoul, et al., 2007) and Middle East (Al-Zarouni and Ghedan, 2012) and (Mirzaei-Paiaman, 2013). Generally, many steps of analysis are performed prior to any hydraulic fracturing job to ensure its effectiveness. But, in comparison, hydraulic fracturing in heterogeneous reservoirs requires much more analysis for an optimum design and operation. This is mainly due to the fact that in heterogeneous reservoirs, rock properties vary dramatically and can affect the hydraulic fracture performance. To overcome the technical and operational challenges associated with hydraulic fracturing in such reservoirs, multi-disciplinary approaches are required to gain improved insight into the hydraulic fracturing performance. This aim can be fulfilled by developing methods to capture the impacts of reservoir heterogeneity, most desirably in a quantitative manner, in a way that the results can be easily translated into reservoir dynamic modelling systems.

Southern North Sea (SNS) reservoirs are among the most heterogeneous reservoirs in which hydraulic fracturing has been considered for implementation. The SNS reservoirs are characterised by their more permeable layers and natural fractures as the two possible elements of heterogeneity (Parvizi, et al, 2015a) and (Parvizi, et al, 2015b). These distinctions make the fraccing designs more complicated and signify the importance of taking an integrated approach to get the most out of the available data. However, integration of different data sources is often not straightforward and requires innovative techniques. This paper introduces a new technique to diagnose the hydraulic fracture performance by 
integrating well test analysis and collecting data at each hydraulic fracturing stage. Upon identification of a technical gap in data integration, this paper proposes an innovative technique for quantifying the impact of heterogeneity on hydraulic fracture performance. Results observed after applying this technique to real field data provide robustness to the method.

There are different approaches to evaluate the well performance of a hydraulically fractured well. Each approach has its own advantages and requires a different level of details for modelling. Accordingly, the prediction reliability depends on the methodology strength in capturing more of the contributing production mechanisms and the underlying physics.

The most common modelling approaches for incorporating the effects of hydraulic fracturing include negative well skin factor (Schulte, 1986), course-grid transmissibility multiplier (El-Ahmady and Wattenbarger, 2004; Iwere et al., 2004), and local grid refinement (LGR) transmissibility modification (Bennett, et al., 1986; Hegre, 1996). The LGR method offers more modelling flexibility since 3D properties with higher resolution can be modelled to help incorporate the reservoir heterogeneity. Ideally, the fracture cell (i.e. the cell which hosts the induced fracture) should have similar width to the induced fracture which can be, for example, in the range of 0.03 to 0.51 inches (based on the data from 24 hydraulic fracture jobs performed in a Southern North Sea field; see Appendix A). Using such small cell sizes violates one of the assumptions of well modelling in finite difference simulators (Peaceman radius formula) and adds error to the well performance calculations. It is also extremely slow and generates convergence problems in numerical reservoir simulations (Hegre, 1996). One solution is to consider thicker fracture cells and upscale the hydraulic fracture conductivity to the fracture cells.

In the presence of natural fractures in tight formations, the physics and modelling become more complicated and challenging. Due to difficulties of designing and performing experimental work on fracture network propagation in the laboratory settings and the difference of laboratory and reservoir scales, numerical modelling has become an essential tool in hydraulic fracture studies, as it facilitates 
incorporation of many details and conditions in modelling and prediction of fracture network geometries (Zhang et al., 2015). Some authors have attempted to simulate hydraulic fracturing in naturally fractured reservoirs considering the complexities involved. Fracture modelling approaches based on the Boundary Element System (BES) were applied by some researchers (Sousa et al., 1993; Zhang et al., 2007; Sessetty and Ghassemi, 2012). Zhao and Young (2009) developed a dynamic 3D Distinct Element Model (DEM) based on tri-axial fracturing laboratory experiments to simulate fluid injection into a reservoir with natural fractures. Ben et al. (2012) used Discontinuous Deformation Analysis (DDA) to simulate hydraulic fracturing. Huang and Ghassemi (2012) used the Virtual Multidimensional Internal Bonds (VMIB) evolution function for numerical simulation of 3D fracture propagation at micro scale. Using this method, they successfully represented the features of tensile and compressive fracture propagation and suggested that 3D simulation of fracture propagation helps understanding and designing multiple hydraulic fractures. Zhang et al. (2016) used the lattice cell version of the discretized virtual internal bond method to model the reservoir rock for numerical simulation of the fracture development behaviour in complex unconventional reservoirs.

Hamidi and Mortazavi (2014) simulated the hydraulic fracture initiation and propagation through intact rock using 3D Distinct Element Code (3DEC) and introducing a fictitious joint technique to facilitate importing the fracture initiation capability in the DEM approach. Zhang et al. (2015) have given a full account of hydraulic fracturing simulation approaches and concluded that Displacement Discontinuity Models (DDM) can best simulate the complex fracture networks.

Considering the fact that most of the numerical fracture modelling approaches are mainly suitable for hard rocks due to assuming planar fracture geometry and linear plastic fracture mechanics, Wang (2015) used Extended Finite Element Method (XFEM) together with Cohesive Zone Method (CZM) and Mohr-Coulomb theory of plasticity to investigate the initiation and development of non-planar fractures in brittle and ductile rocks. To address the same issues and investigate non-planar hydraulic fractures by 3D simulation, Sobhaniaragh et al. (2016) also combined the Cohesive segments with 
Phantom Node Method and called it CPNM. Nadimi et al. (2016) presented a new meshfree 3D simulation model based on Peridynamic (PD) method for investigation of hydraulic fracture development and geometry in complex and heterogenous formations; the method also considers the 101 interaction of the induced fractures with the natural fractures.

102 Despite their basic nature, coupling of these models with a commercial simulator for investigating the 103 interaction of induced fractures with natural fractures is difficult and currently not fully practical. 104 Therefore, on performance evaluation of hydraulic fractures, a methodology is required that can: investigators so far. In this work, the authors suggest that such a technical gap can be filled through integration of well test results with fracturing operational data analysis for diagnosing and evaluating 113 hydraulic fracturing performance. To link the hydraulic fracturing modelling with well test 114 interpretation, in this paper, a new methodology is proposed to quantify the heterogeneity impact on 115 hydraulic fracture performance in terms of a new parameter defined as Heterogeneity Impact Factor 116 (HIF). This parameter represents a quantified value for the expected performance of hydraulic 117 fracturing on each well considering the contribution of heterogeneity. HIF creates a basis for 118 comparing the wells of the same field with each other and also can exhibit the degree of heterogeneity 119 in different fields. 
Quantification of heterogeneity impact as a value is important as it can be used for prediction of well production by integrating the tools of production simulation with HIF. The way forward is to work on a new methodology of integrating HIF with Decline Curve Analysis.

The results of the application of the proposed technique in one of the SNS reservoirs were in very good agreement with geological and drilling observations. The HIF analysis was then incorporated into the dynamic simulation model and pressure predictions of the model were compared with the three-week annual shut-down. The build-up response and its derivative displayed an excellent match which provides evidence of successful application of the proposed technique.

In the following sections, first, the workflow introduced by the authors in a previous study (Parvizi, et al, 2015b) to analyse the hydraulic fracture performance is discussed. In that study, an integrated multidisciplinary approach was proposed for deploying the data and information available all the way from seismic interpretation to reservoir dynamic modelling to evaluate the performance of the hydraulic fracturing. It should be noted that the current work is, in fact, a continuation of the previous study and the newly proposed HIF analysis is built upon the foundation of the hydraulic fracture performance investigation, the relation between them can be used to conclude a zero-dimension property of the 
are compared with geological evidences and validated by matching the pressure predictions of the resulting dynamic reservoir model with the real well test data.

\section{Methodology: Hydraulic Fracture Performance Analysis Workflow}

In this section, the details of application of the comprehensive workflow of hydraulic fracture performance analysis introduced by the authors in a previous publication (Parvizi, et al, 2015b) is presented. In this work, actual field data was acquired from an oil and gas operator with the view to evaluate the hydraulic fracture performance.

This field is situated in the Southern North Sea gas basin. It is $10 \mathrm{~km}$ long, $1.5 \mathrm{~km}$ wide with an estimated reservoir thickness of $270 \mathrm{ft}$. The reservoir rock is of Rotliegend age, mainly sandstone with layers of siltstone and minor shale deposits, according to log and core data. This producing horizon is overlain by a 400-feet shale formation which constrains the propagation of the fractures. The reservoir formation is also underlain by a very tight sandstone with unsuccessful attempts of production which render it unexpected to have noticeable contribution to production of fluids. Based on core data, the reservoir porosity ranges from 5 to 20 percent and the average reservoir permeability is less than 1 $\mathrm{mD}$. Slightly higher permeabilities are observed where the reservoir formation is encountered in wells at lower depths with less illitisation.

The initial well test, done on the exploration well in the 1980's, had indicated a gas flow rate of 4 MMSCFD; the low rate was attributed to the significantly illitised formation. An appraisal well was drilled 16 years later and flowed 10 MMSCFD. A phased development plan was prepared with three of the five initially planned horizontal wells (A, B, and C) being drilled and fracced each with five stages. The two remaining wells were drilled after three years of production. These wells were also horizontal each with five stage frac zones (D and E), similar to phase-1 wells.

Performance evaluation of these multi-fracced horizontal wells is crucial for forecasting and evaluating further development opportunities. To simulate the hydraulic fracture in this study, pseudo 3D 
hydraulic fracture modelling was performed using a commercial simulator for fracture design and analysis in complex situations. However, it should be noted that, in this paper, the focus is on the combined use of hydraulic fracture modelling results and pressure decline analysis results regardless of the specific methodologies/ software used for obtaining such results. In other words, in any other similar study, once the fracture modelling is performed using any approach chosen by the engineer/ researcher, the results can be integrated with the results of well test analysis, which could, in turn, be accomplished using any method selected. Such integration of the results is then governed by the workflow presented here.

A complete picture of the hydraulic fracturing modelling workflow requires an integrated multidisciplinary approach to be applied. This systematic workflow is shown in Figure 1 based on an ideal approach of deploying multi-disciplinary information.

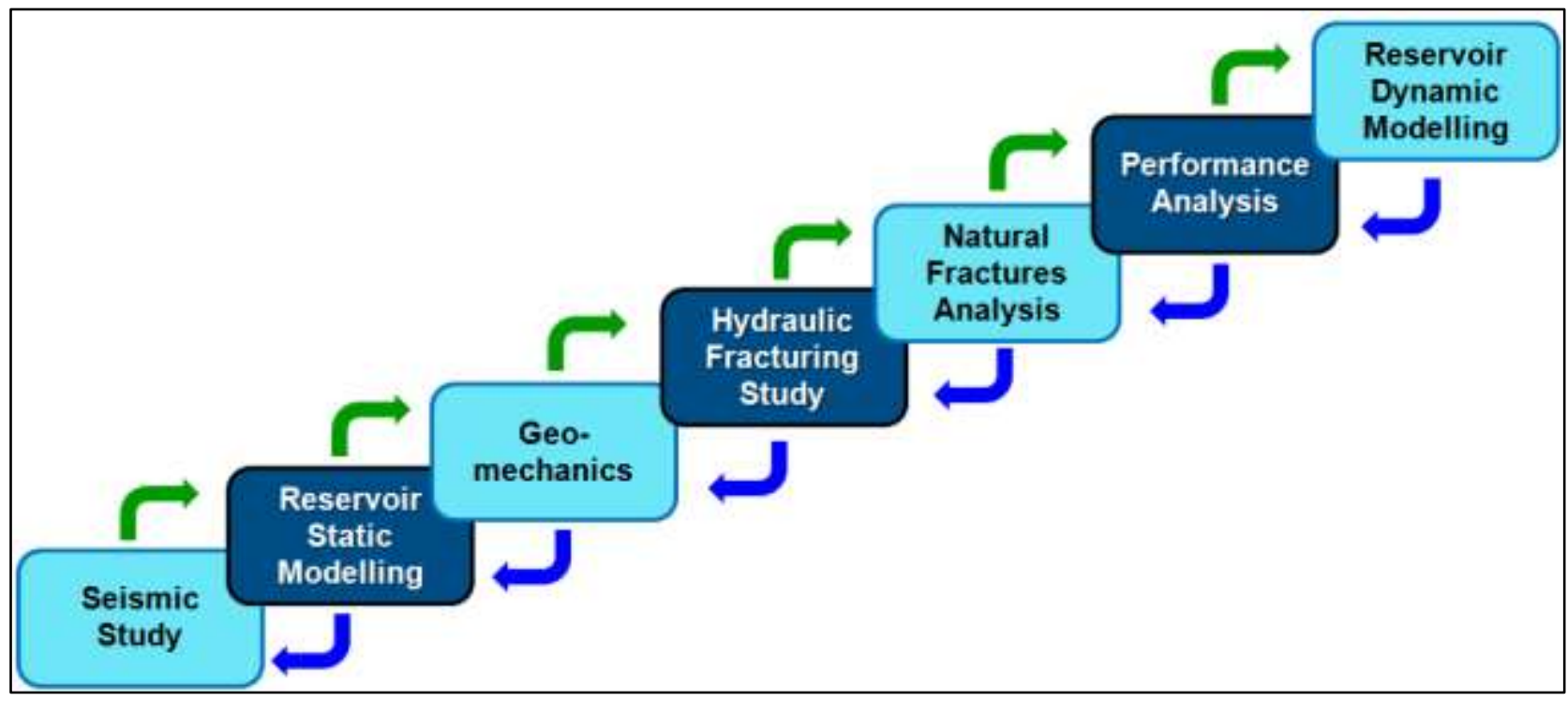

Figure 1. Integrated hydraulic fracturing modelling workflow proposed by Parvizi et al. (2015b).

The workflow ends in creating 3D static and dynamic models. Some of the fundamental inputs to the workflow of hydraulic fracture performance evaluation are:

1. Results of net pressure match

2. Well test interpretations (pressure transient analysis) 
3. PLT outcomes (production-data analyses)

4. Hydraulic fracture conductivity versus effective stress

The details of each input as well as their integration in the fracture modelling are as follows:

\subsection{Net Pressure Analysis}

The difference between the pressure in the fracture and the in-situ stress $\left(\mathrm{P}_{\mathrm{f}}-\right.$ in-situ stress $)$ is referred to as the net pressure. To estimate the patterns of growth for fractures in the field or after the treatment, the behaviour of net-pressure was defined by Nolte and Smith (1981). In their analysis method, they used the model proposed by by Perkins and Kern (1961) and later modified by Nordgren (1972) and hence called Perkins-Kern-Nordgren (PKN) theory. Based on the assumptions of the PKN theory, as long as the fracture height is contained, the net pressure will increase with time according to the following proportionality:

$P_{n} \propto \Delta t^{e}$

Where $\mathrm{P}_{n}$ is critical net pressure and $\Delta \mathrm{t}$ is change in time with $0.125<\mathrm{e}<0.20$, and, slope, $\mathrm{e}=0.20$ for low leakoff and 0.125 for high leakoff. Leak off is a measure of the fracture fluid-loss when the pumping stops (Economides and Nolte, 2000).

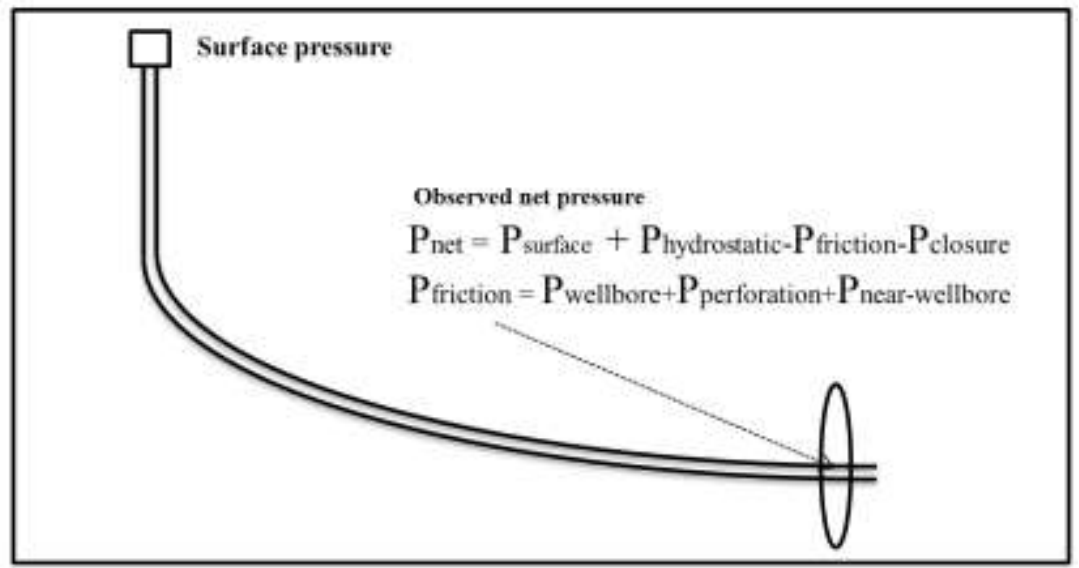

Figure 2. Net pressure calculation diagram.

202 Figure 2 is generated based on net pressure formulas Nolte and Smith (1981) defined. This Figure 
shows the relationship between net pressure and the rest of measurements during fracturing operation.

204 Fracture geometry is inferred from net pressure and leak-off behaviour in this indirect diagnostic technique. The results of net-pressure match interpretations are non-unique so careful application is

206 required. This technique is most useful when results are integrated or calibrated with results of other 207 diagnostics.

208 In a hydraulic fracturing job, the injection parameters (i.e. surface pressure, bottomhole pressure, flow 209 rate, fluid volumes, and proppant concentration) are recorded in real-time and fed into hydraulic 210 fracture modelling software. The software utilizes the closure stress profile and rock mechanical 211 properties from the static model to match the net pressure obtained from the injection parameters and 212 leak-off behaviour.

213 Through net pressure matching, an estimate of the fracture half-length $\mathrm{x}_{\mathrm{f}}$, fracture height $\mathrm{h}_{\mathrm{f}}$, fracture 214 width $\mathrm{w}_{\mathrm{f}}$ and its conductivity $\mathrm{C}_{\mathrm{fD}}$ was achieved for the number of fracture jobs implemented in this 215 field (Table 1).

\section{$216 \quad 2.2$ Well Test (Pressure Transient) Analysis}

217 It is possible to estimate of the number of active hydraulic fractures, their average fracture geometry 218 (fracture height and half-length) and their average conductivity using well test analysis. Clarkson 219 (2013) described very detailed and comprehensive approach of production data analysis including well 220 test interpretation for unconventional resources. There are three analytical well test models describing 221 fluid flow and pressure behaviour of hydraulic fractures:

- Infinite conductivity hydraulic fractures

- Uniform flux hydraulic fractures

- Finite conductivity hydraulic fractures 
225 In infinite conductivity hydraulic fractures, it is assumed that pressure drop along the fracture is 226 negligible; therefore, fracture linear or bilinear flows are not practically observed. On a logarithmic 227 plot, the formation linear flow is seen with a slope of 0.5 followed by a pseudo-radial flow for which 228 the derivative becomes horizontal.

229 Flow in uniform flux hydraulic fractures behaves very similarly to infinite conductivity fracture, except 230 that the flow is assumed uniform along the fracture length. Formation linear flow and pseudo-radial 231 flow regimes can be observed if flow duration is long enough.

232 There is a considerable pressure drop along the finite conductivity hydraulic fractures, therefore 233 bilinear flow (fracture linear flow and formation linear flow) occurs at early times. Bilinear flow is 234 observed with the slope of 0.25 on the pressure derivate plot. Then linear formation flow may or may 235 not be seen, because it is very short and finally, pseudo-radial pressure behaviour is developed. During 236 the well test matching process of the five multi-staged fractured horizontal wells, finite conductivity 237 hydraulic fractures was assumed. This is because of uniform flux and infinite conductivity fracture assumption lead to a different pattern of pressure behaviour comparing with the real data.

\section{$239 \quad 2.3$ Production Data Analysis}

240 Productivity of each fracture may be obtained from PLT analysis and deployed to validate the expected 241 flow contribution from net-pressure analysis, to check the number of active fractures obtained from 242 well test interpretation and to tune the dynamic model. It is commonly believed that a hydraulic 243 fracture with higher proppant concentration should perform better however, due to heterogeneity it 244 may be difficult to find a correlation between hydraulic fracture geometry, its proppant coverage and production performance. Therefore, PLT has a key role for understanding the effect of heterogeneity on the fracture performance. 


\subsection{Hydraulic Fracture Conductivity versus Effective Stress}

248 Conductivity of the fracture will be reduced during the life of the well because of increasing stress on

249 the propping agents. The effective stress on the propping agent is the difference between the in-situ 250 stress and the flowing pressure in the fracture. As the well is produced, the effective stress on the 251 propping agent will normally increase, because flowing bottomhole pressure will be decreasing. 252 Parvizi et al. (2015b) explained the workflow of integration of this mechanism into the dynamic model. 253 This effect is measured in the laboratory by measuring the fracture conductivity with increasing 254 effective stress on proppants and the conductivity versus effective stress is obtained (Figure 3-a). The results are then translated into the dynamic model in the form of a fracture transmissibility multiplier versus pressure table (Figure 3-b). Grid cells that represent the fracture in the model could then be assigned the fracture transmissibility multiplier versus pressure table that was created as illustrated in Figure 3.

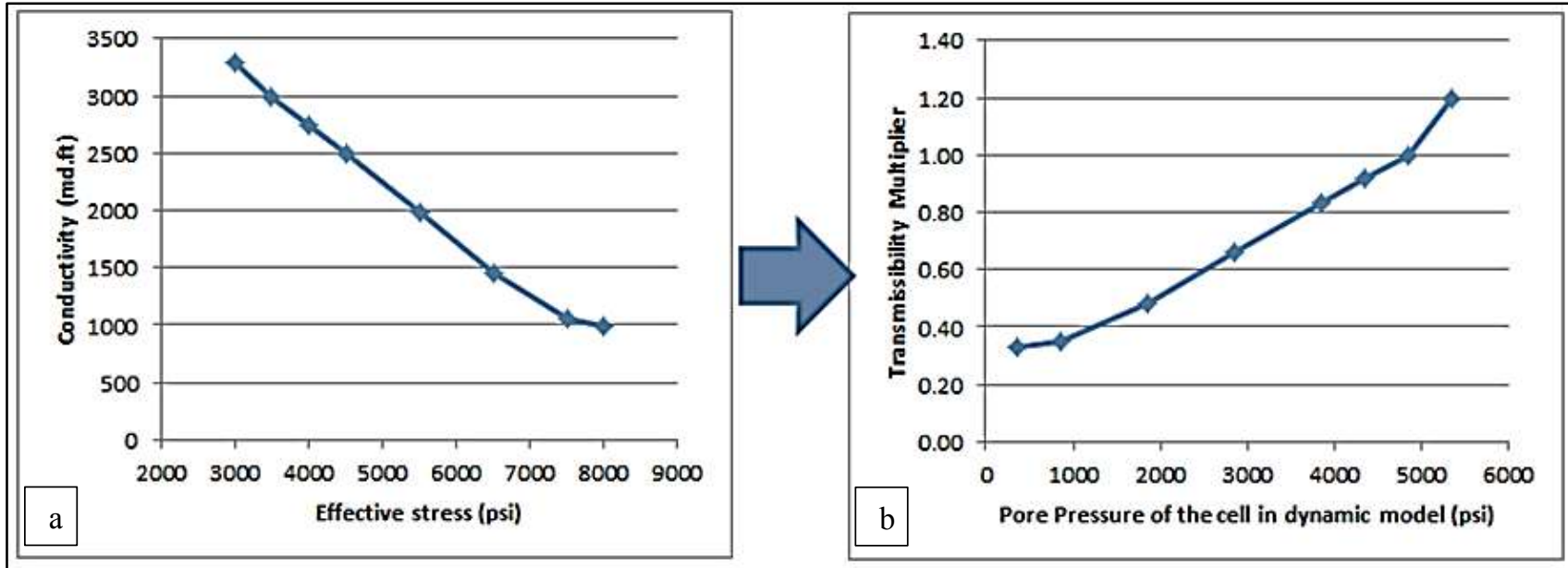

Figure 3. Translating fracture conductivity versus proppant stress (a) into fracture transmissibility multiplier versus pressure (b) (Parvizi, et al, 2015a).

An important step in this study is the integration of the results of net pressure analysis with the outcome of the analysis performed in this section on the change of fracture conductivity with effective stress. Such integration is seen as a challenge due to the fact that the nature and detail level of these parameters and analyses are different and there has not been a practical technique to capture and successfully 
combine all the information gained through the application of each method. The following section presents the way in which this challenge is overcome.

\subsection{Integration of Net Pressure Match, Well Test Data, PLT Results and Connectivity Behaviour}

269 Generally, the process of hydraulic fracture description involves using fracture design software to match the net-pressure and report the fracture geometry (height, and half-length) and attributes such

271 as conductivity for each fracture. Post-job well test (well test carried out after hydraulic fracturing and 272 cleaning up) is the main reference to show the performance of the well. The problem is that the assumptions of fracture in well test interpretation are based on an average fracture attribute and 274 geometry. This makes the comparison very difficult.

275 In order to evaluate fracture performance, we define a measurable parameter named Surface 276 Conductivity $\left(\mathrm{SC}_{\mathrm{f}}\right)$ for the hydraulic fractures. This parameter should be an indication of the expected 277 fracture performance; thus, $\mathrm{SC}_{\mathrm{f}}$ is directly proportional to fracture conductivity and its dimensions. 278 Therefore;

$279 S C_{f} \propto K_{f} \cdot w$

$280 S C_{f} \propto 2 . X_{f}$

$281 S C_{f} \propto h_{f}$

282 Where $\mathrm{K}_{\mathrm{f} . \mathrm{W}}$ is conductivity of hydraulic fracture, $\mathrm{x}_{\mathrm{f}}$ is hydraulic fracture half length, and $\mathrm{h}_{\mathrm{f}}$ is hydraulic 283 fracture height. Then, $\mathrm{SC}_{\mathrm{f}}$ can be defined as fracture surface multiplied by fracture conductivity 284 (Equation 1). The unit of $\mathrm{SC}_{\mathrm{f}}$ would be $\mathrm{mD} \cdot \mathrm{ft}^{3}$, but for simplicity of the analysis, the values would be 285 presented in $10^{6} \mathrm{mD} . \mathrm{ft}^{3}$ since the typical values for such a parameter will be in the order of $10^{6}$ to $10^{9}$. 
In order to generalise the concept of $\mathrm{SC}_{\mathrm{f}}$ for the wells with more than one fracture, $\mathrm{SC}$ is defined for such wells as the summation of all the $\mathrm{SC}_{\mathrm{f}}$ values of the fractures in the well (Equation 2).

290 Integrating all the hydraulic fracture properties into one single parameter is the key advantage of SC.

291 It can therefore, be calculated for well test analysis outcome as well as net pressure match; Equation 3 292 and Equation 4.

$293 \quad S C_{W T A}=\sum_{i=1}^{n} 2 x_{f} \times h_{f} \times K_{f} \cdot w$ Equation 3.

Where

WTA $=$ Well test analysis (post-frac well test)

$\mathrm{NPM}=$ Net pressure match for the fracture job

$\mathrm{n}=$ Number of hydraulic fractures that are assumed for well test match $\mathrm{m}=$ Number of hydraulic fractures that are designed in hydraulic fracture design software

300 In order to integrate the results from the net pressure match and well test analysis, a new parameter is proposed to be calculated: the WTA/NPM ratio (Equation 5). This ratio is the comparison of the product of fracture surface area $\left(\mathrm{x}_{\mathrm{f} .} \mathrm{h}_{\mathrm{f}}\right)$ and fracture conductivity $\left(\mathrm{k}_{\mathrm{f} . \mathrm{w}}\right)$ between the results derived from well test analysis and net pressure matching. This ratio solves the issue of having different levels of details for net-pressure-match versus well test analysis.

WTA/NPM ratio will be defined as:

$S C_{W T A} / S C_{N P M}=\left(\sum_{i=1}^{n} 2 x_{f} \times h_{f} \times K_{f} \cdot w\right)_{W T A} /\left(\sum_{i=1}^{m} 2 x_{f} \times h_{f} \times K_{f} \cdot w\right)_{N P M}$ 
This ratio is then used to adjust the fracture conductivity in the dynamic simulation model using the 309 proposed workflow shown in the Figure 4.

-By Net-pressure analysis, obtain:

- Frature dimensions

- Fracture conductivity

-By well test analysis, calculate:

- Average frature dimensions per well

-Average fracture conductivity per well

- Calculate WTA/NPM ratio

- Multiply the NPM interpreted fracture conductivity by WTA/NPM ratio

- Use the obtained fracture conductivity in dynamic model

-Apply fracture conductivity behaviour versus pore pressure in dynamic model

- Compare the results with PLT

Figure 4. Workflow for integration of NPM, WTA, fracture conductivity behaviour and checking against PLT data.

This technique has the following advantages:

1. It reduces the uncertainty of net pressure match output by a truth-checking scaling factor.

2. It makes history matching easier by improving initial guess accuracy.

3. It is able to correlate data from a source with fewer dimensions (well test analysis) to another source with higher level of dimensions (conductivity distribution in fracture cells).

4. It gets the benefits of both techniques: details from net pressure match and validation from well test and production data.

5. It captures the dynamics of connectivity and makes the forecasting more reliable.

This technique is validated by real field data and the results are discussed in the next section. 


\section{Results and Discussion}

323 In this section, the application of the proposed technique on the field data is presented in a case study 324 manner. First, as a diagnostic tool for fracced well performance, the WTA/NPM analysis is performed 325 and cross checked with geological observations to support the conclusion. Then, production data (PLT) 326 is shown to be in agreement with the findings of he WTA/NPM analysis. The impact of WTA/NPM ratio on reservoir dynamic modelling is discussed in details. Finally, the results of application of the proposed technique are validated using actual field data and evidences.

\subsection{WTA/NPM Analysis: A new proposed ratio for fracced well performance}

330 Well test interpretation has been carried out on each of the wells and the results in terms of fracture model (FC: finite conductivity), fracture conductivity (permeability $\mathrm{x}$ width), fracture half-length and fracture height are presented in the first section of Table 1. Interpretation of the net-pressure analysis per fracture (total of 24 fractures initiated) and the outcome in terms of fracture connectivity, fracture half-length and fracture height is reported in the last section of this table. Using Equation 5, $\mathrm{SC}_{\mathrm{WTA}} / \mathrm{SC}_{\mathrm{NPM}}$ is calculated and stated in the column of WTA/NPM. WTA/NPM of $100 \%$ means the well behaves as it has been modelled. The range of WTA/NPM for this field varies from $35 \%$ to $174 \%$ which shows the wells which underperformed (Well B, D and E) or far outperformed (well A); Table 1.

\begin{tabular}{|c|c|c|c|c|c|c|c|c|c|c|}
\hline \multirow[b]{2}{*}{ Well } & \multicolumn{5}{|c|}{ Well test analysis per well } & \multirow[b]{2}{*}{ WTA/NPM } & \multicolumn{4}{|c|}{ Net pressure match per fracture } \\
\hline & $\begin{array}{c}\text { Fracture } \\
\text { Model }\end{array}$ & $\begin{array}{l}\text { Kf.W } \\
\text { (Frac) } \\
\text { mD.ft }\end{array}$ & $\begin{array}{l}\text { No. of } \\
\text { Fractures }\end{array}$ & $\begin{array}{l}\text { Fracture } \\
\text { Half } \\
\text { Length } \\
\text { (ft) } \\
\end{array}$ & $\begin{array}{l}\text { Fracture } \\
\text { Height } \\
\text { (ft) }\end{array}$ & & $\begin{array}{l}\text { Average* } \\
\text { Kf.W } \\
\text { (Frac) } \\
\text { mD.ft }\end{array}$ & $\begin{array}{l}\text { Fracture } \\
\text { Half } \\
\text { Length } \\
\text { (ft) } \\
\end{array}$ & $\begin{array}{l}\text { Fracture } \\
\text { Height } \\
\text { (ft) }\end{array}$ & $\begin{array}{l}\text { Kf.W } \\
\text { (Frac) } \\
\text { mD.ft }\end{array}$ \\
\hline \multirow{5}{*}{ A } & \multirow{5}{*}{ FC } & \multirow{5}{*}{2500} & \multirow{5}{*}{4} & \multirow{5}{*}{300} & \multirow{5}{*}{250} & \multirow{5}{*}{$174 \%$} & \multirow{5}{*}{2039} & 220 & 230 & 1088 \\
\hline & & & & & & & & 200 & 220 & 3099 \\
\hline & & & & & & & & 200 & 120 & 1596 \\
\hline & & & & & & & & 250 & 180 & 1840 \\
\hline & & & & & & & & 200 & 240 & 2478 \\
\hline \multirow{3}{*}{ B } & \multirow{3}{*}{$\mathrm{FC}$} & \multirow{3}{*}{1000} & \multirow{3}{*}{4} & \multirow{3}{*}{200} & \multirow{3}{*}{250} & \multirow{3}{*}{$63 \%$} & \multirow{3}{*}{1567} & 175 & 75 & 632 \\
\hline & & & & & & & & 210 & 250 & 403 \\
\hline & & & & & & & & 350 & 150 & 2169 \\
\hline
\end{tabular}




\begin{tabular}{|c|c|c|c|c|c|c|c|c|c|c|}
\hline & & & & & & & & 220 & 230 & 2106 \\
\hline & & & & & & & & 150 & 220 & 2008 \\
\hline \multirow{5}{*}{$\mathrm{C}$} & \multirow{5}{*}{$\mathrm{FC}$} & \multirow{5}{*}{500} & \multirow{5}{*}{3} & \multirow{5}{*}{200} & \multirow{5}{*}{250} & \multirow{5}{*}{$104 \%$} & \multirow{5}{*}{802} & 200 & 60 & 195 \\
\hline & & & & & & & & 150 & 110 & 353 \\
\hline & & & & & & & & 252 & 198 & 1227 \\
\hline & & & & & & & & 320 & 160 & 463 \\
\hline & & & & & & & & 260 & 140 & 1102 \\
\hline \multirow{4}{*}{ D } & \multirow{4}{*}{$\mathrm{FC}$} & \multirow{4}{*}{1220} & \multirow{4}{*}{3} & \multirow{4}{*}{202} & \multirow{4}{*}{150} & \multirow{4}{*}{$35 \%$} & \multirow{4}{*}{1279} & 420 & 150 & 2489 \\
\hline & & & & & & & & 350 & 180 & 1512 \\
\hline & & & & & & & & 580 & 115 & 601 \\
\hline & & & & & & & & 425 & 130 & 453 \\
\hline \multirow{5}{*}{$\mathrm{E}$} & \multirow{5}{*}{ FC } & \multirow{5}{*}{2579} & \multirow{5}{*}{5} & \multirow{5}{*}{132} & \multirow{5}{*}{250} & \multirow{5}{*}{$85 \%$} & \multirow{5}{*}{2306} & 320 & 190 & 2043 \\
\hline & & & & & & & & 240 & 150 & 2075 \\
\hline & & & & & & & & 350 & 170 & 2216 \\
\hline & & & & & & & & 125 & 210 & 3251 \\
\hline & & & & & & & & 155 & 230 & 2442 \\
\hline
\end{tabular}

Table 1. Results of WTA/NPM analysis of an actual field data in addition to calculated fracture dimensions and conductivity by well test analysis and net pressure match.

341 The calculated WTA/NTM ratios lead to observations summarized in Table 2.

\begin{tabular}{|c|c|l|}
\hline Well & WTA/NPM & \multicolumn{1}{|c|}{ Explanations } \\
\hline A & $174 \%$ & Well productivity is exceptionally higher than the expected fracturing performance \\
\hline B & $63 \%$ & Well productivity is less than the expected fracturing performance \\
\hline C & $104 \%$ & $\begin{array}{l}\text { NPM and WTA are in a good agreement i.e. the well productivity and interpreted } \\
\text { fracture performances are similar. }\end{array}$ \\
\hline D & $35 \%$ & $\begin{array}{l}\text { There is a problem in the well/reservoir that causes the well productivity to be so } \\
\text { lower than the expected performance. }\end{array}$ \\
\hline E & $85 \%$ & Well productivity and interpreted fracture performance are similar. \\
\hline
\end{tabular}

343 Using the calculated WTA/NPM, we introduce a new parameter called heterogeneity impact factor 344 (HIF) defined as below:

HIF quantifies the heterogeneity impact on hydraulic fracture performance because it is related to the results of the observed data and considers the production period and the aerial extent of reservoir 
properties in comparison to what has been expected by the performance of the fraccing job. Generally, when the same fracture propagation is interpreted by different engineers/ researchers, different solutions in terms of fracture half length and height are obtained. The solutions with higher fracture half lengths usually have lower fracture height interpretations and vice versa. This gives rise to nonunique solutions for the same problem (Warpinski et al., 1994). HIF analysis, however, is basically using the multiplication of the fracture half length and fracture height, thus relaxing the solution against different interpretations. Furthermore, HIF analysis is, indeed, a repeatable workflow that can be run several times by adjusting the input parameters in their uncertainty range until the HIF uncertainty distribution is obtained based on which the rest calculations are performed.

Figure 5 shows the results of HIF\% on the real field case. Well A far outperformed the expected hydraulic fracture performance whereas Well D dramatically underperformed. In the next section, we discuss the geological features to confirm the results.

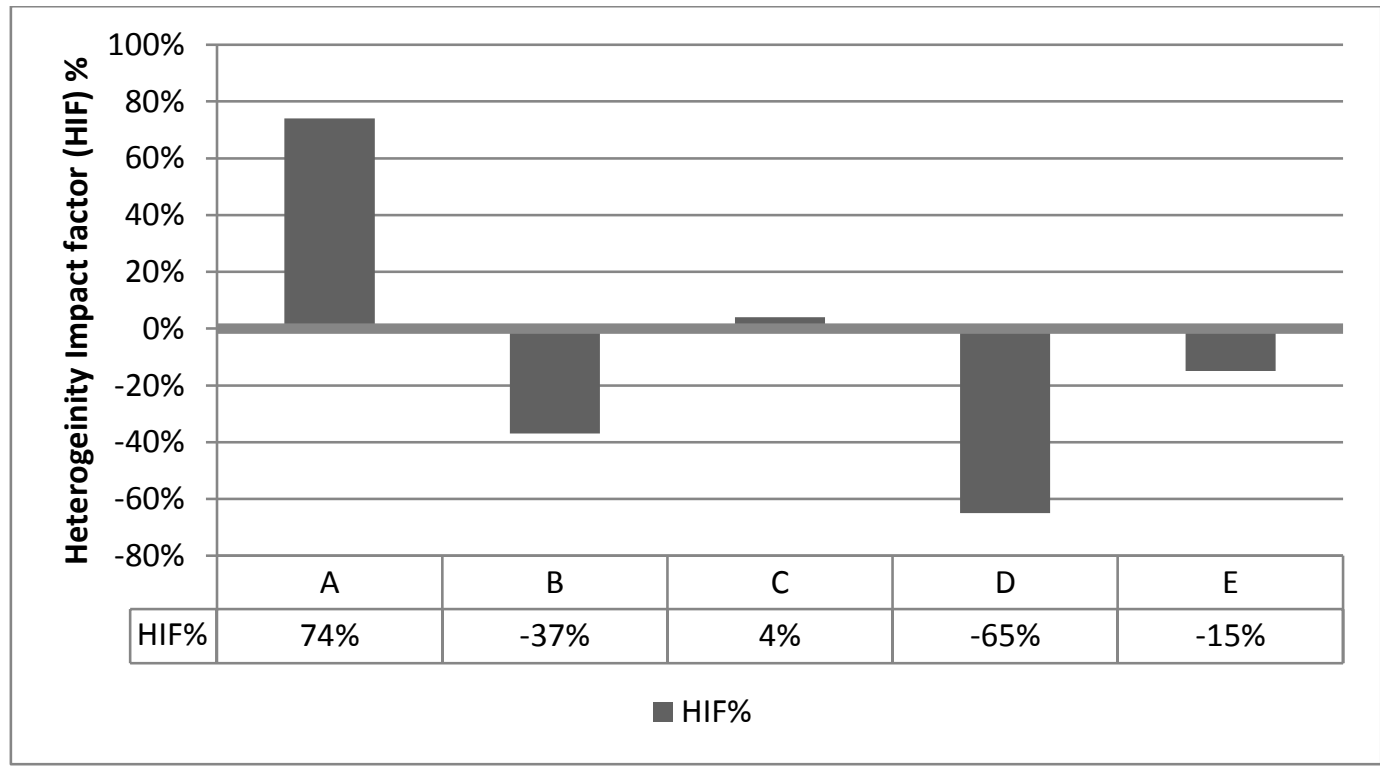

Figure 5. Calculated heterogeneity impact factor per well.

\subsection{Geological Evidences Supporting the Results of WTA/NPA Analysis}

Well A has five fracturing zones in which zone 1 is the deepest and zone 5 is the shallowest, as 
which is much higher than the rest of the wells in this field. This means that there is remarkable difference between the hydraulic fracture performance expectations (net pressure match) versus the term WTA that is related to the production behaviour over a longer period. This is an indication of the presence of an extra production mechanism that may be interpreted as natural fracture and/or more permeable sands. This interpretation is confirmed by high mud-losses observed in the drilling report and logging-while-drilling (LWD) image logs.

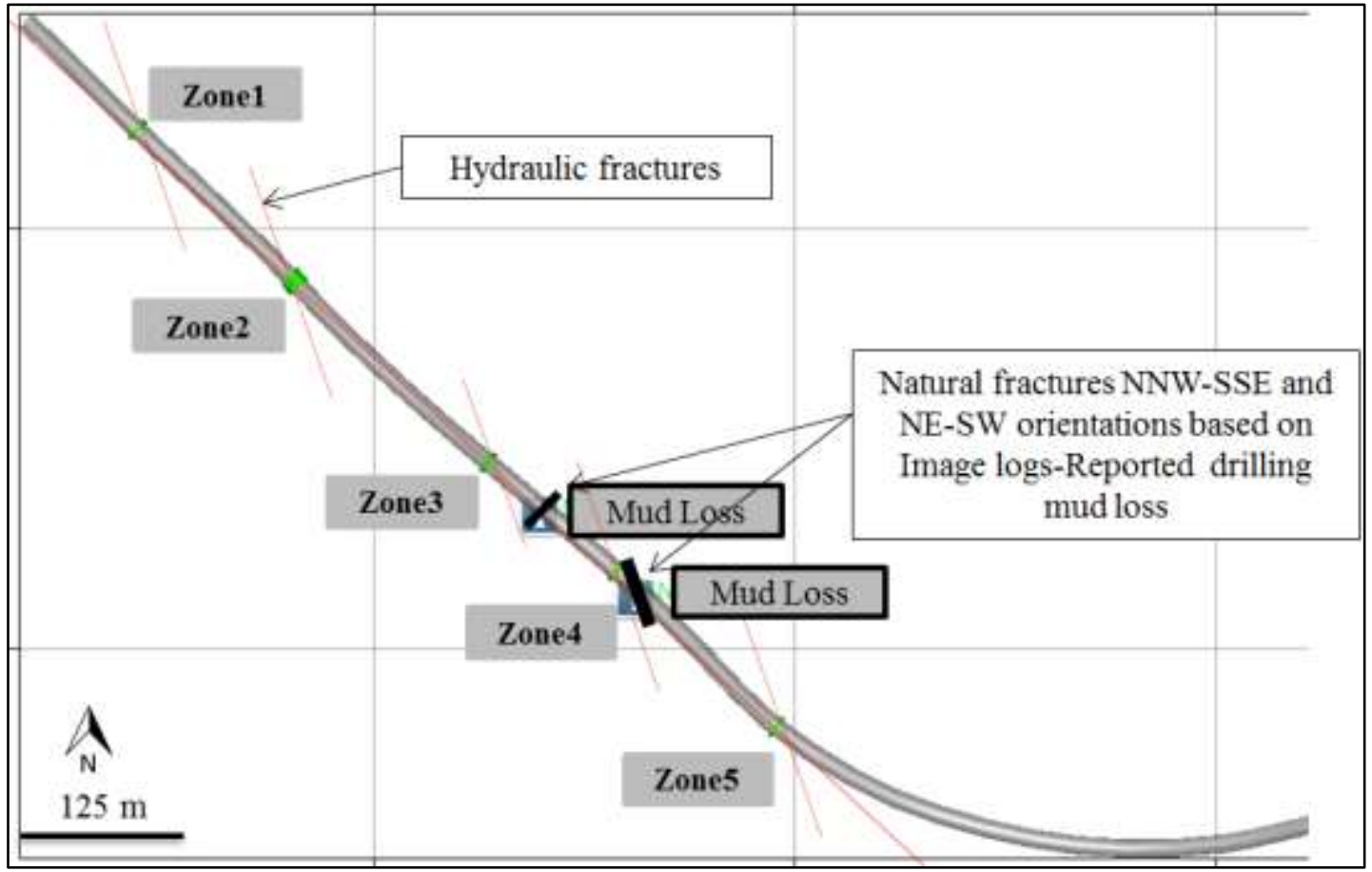

Figure 6. Well A trajectory, hydraulic fractures and mud loss positions.

373 Static losses of approximately $41 \mathrm{bbl} / \mathrm{hr}$ were observed at $13,326 \mathrm{ft}$ MD and dynamic losses of approximately $20 \mathrm{bbl} / \mathrm{hr}$ were observed at $13,444 \mathrm{ft}$ MD. Based on the analysis of the density image logs, it was found that the mud losses coincide with the presence of a cluster of low-density features shown in Figure 7. The two features presented in the blue intervals of Figure 7 (a) and Figure 7 (b) were interpreted as open fractures filled with drilling mud. 
(a)

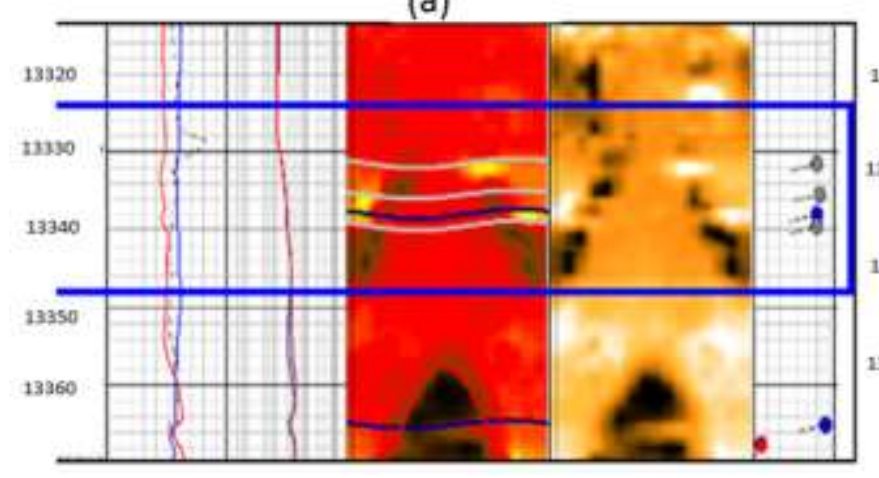

(b)

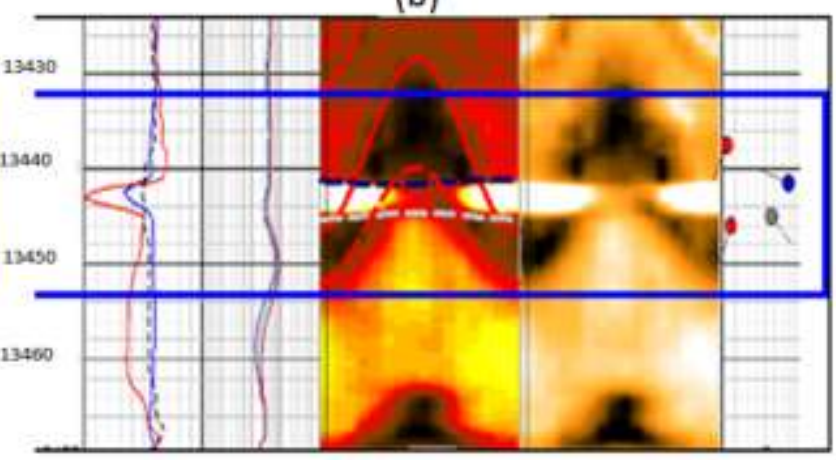

Figure 7. Density image logs show open fractures in the same regions where drilling mud losses happend while drilling Well A.

Aside from the two intervals where open fractures were interpreted, there was a substantial increase in the leakoff coefficient from the mini-frac $(0.0065 \mathrm{ft} / \sqrt{\mathrm{min}})$ in zone 4 of Well A (perforation depth interval 13280-13290 ft MD); a mini-frac is performed without proppant and used as a diagnostic to aid with the final design of the main frac job. The main-frac (with proppant) of zone 4 had the highest leak off coefficient of $0.008 \mathrm{ft} / \sqrt{ } \mathrm{min}$. This further substantiated the existence of a higher permeable region that is connected to the hydraulic fracture. Figure 6 illustrates the trajectory, hydraulic fractures and reported mud-loss positions during drilling.

\subsection{Production Data and Application of Proposed Fracture Performance Ratio}

The PLT design was for two flowing passes, one at low rate the other at a high rate and one shut-in pass to evaluate the contribution of flow from each fracture. The tool was run in on wireline with the assistance of a tractor. Table 3 is a summary of the PLT results for Well A.

\begin{tabular}{|c|c|c|c|c|c|}
\hline $\begin{array}{c}\text { Zon } \\
\mathrm{e}\end{array}$ & $\begin{array}{c}\text { Fracture half length } \\
(\mathrm{ft})\end{array}$ & $\begin{array}{c}\text { Fracture height } \\
(\mathrm{ft})\end{array}$ & $\begin{array}{c}\text { Fracture Kf.W } \\
(\mathrm{mD} . \mathrm{ft})\end{array}$ & $\begin{array}{c}\text { SC (NPM) } 10^{6} \\
\text { mD.ft3 }\end{array}$ & $\begin{array}{c}\text { PLT flow } \\
\text { contribution \% }\end{array}$ \\
\hline 1 & 220 & 230 & 1088 & 110 & $\mathbf{2 4 \%}$ \\
\hline 2 & 200 & 220 & 3099 & 273 & $\mathbf{1 4 \%}$ \\
\hline 3 & 200 & 120 & 1596 & 77 & $\mathbf{4 \%}$ \\
\hline 4 & 250 & 180 & 1840 & 166 & $\mathbf{2 2 \%}$ \\
\hline
\end{tabular}


Table 3. PLT results summary for Well A compared with hydraulic fracture geometry from net pressure match

A comparison of the SC vs PLT results is presented in Figure 8. The following observations have been made:

Zone 1: The gas flow contribution is higher than the expected fracture performance. This can be due to higher porosity at this region which needs seismic inversion techniques to be confirmed. This will be investigated in next stage of this study.

Zone 2: The gas flow contribution of this zone is consistent with SC(NPM) analysis. Low fracture height caused the vertical confinement of hydraulic fracture.

Zone 3: The gas flow contribution of this zone is consistent with SC(NPM) analysis.

Zone 4: The gas flow contribution of this zone is higher than expected fracture performance based on SC(NPM) analysis. This is linked to the high WTA/NPM ratio of well A. Observations on image logs and drilling mud loss report on this zone confirmed open natural fractures.

Zone 5: This zone is not connected to natural fractures by geological evidences but the production logging results suggest the hydraulic fractures of this zone must be connected to higher permeability conduits such as more permeable sands. In appraisal wells of this field, the more permeable sands were observed in shallower geological layers than target layers for Well A. The thickness, extension and permeability of these sands are a history matching parameters for the dynamic model. Having defined all the properties and then applying the WTA/NPM technique to longer the period of production, the history matching parameters are adjusted to obtain a geologically valid thickness, lateral extension and possible permeability of theses conduits. 
Based on such analysis, WTA/NPM ratio and production data are linked and aligned.

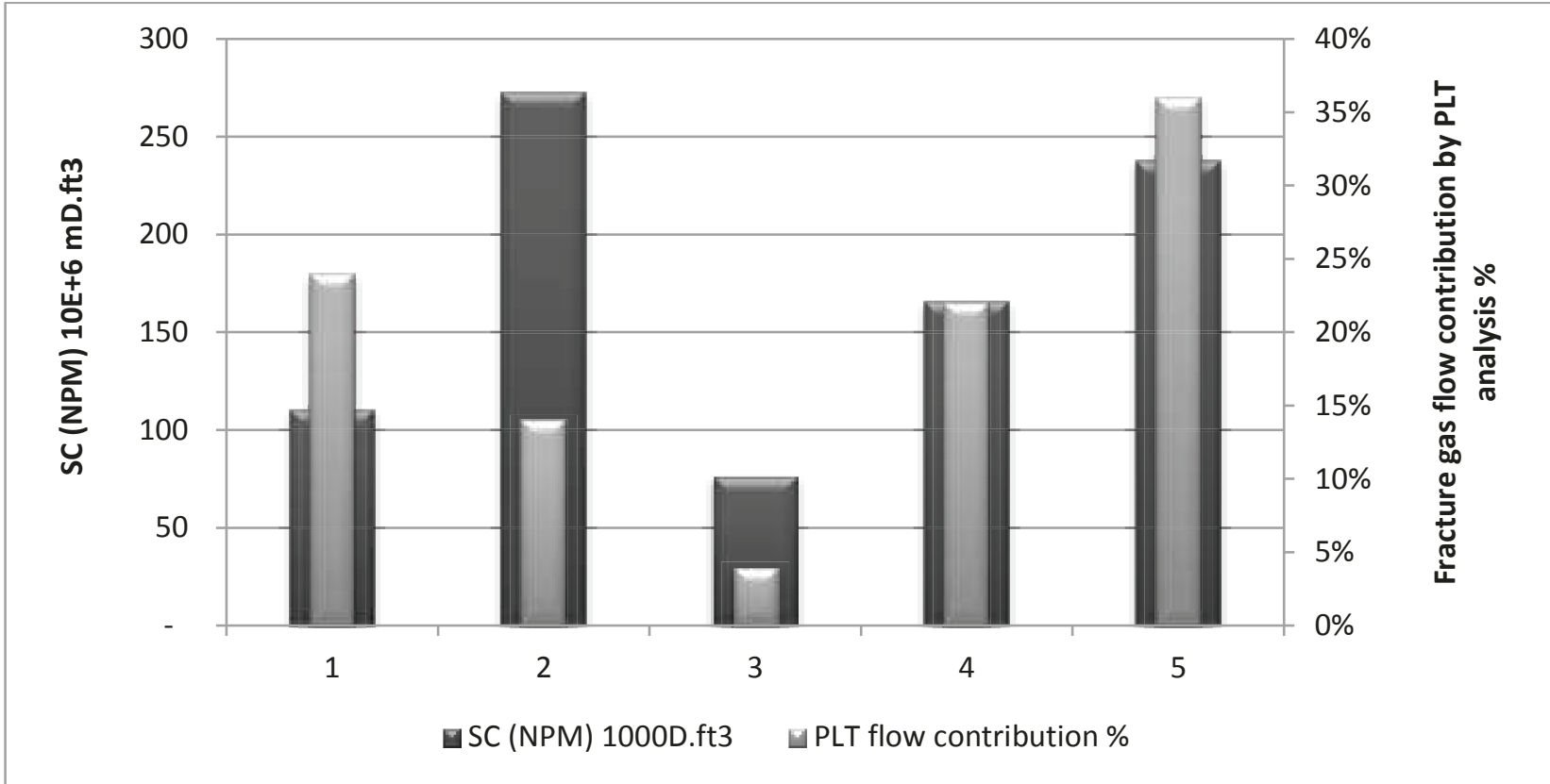

Figure 8. Comparison of SC (NPM) with PLT gas flow contribution

\subsection{Impact of WTA/NPM ratio on Reservoir Dynamic Modelling}

WTA/NPM technique identifies the wells which need to be tuned for having more reliable models.

The workflow of scaling the fracture cell properties is explained in Figure 4. The dynamic model is created using LGR method to have more resolution around the wellbore. Having completed the workflow (Figure 4), the dynamic model should be history matched using a reservoir simulator. The reservoir simulator is run to compare the results of the input assumptions described in the above sections with the real field data. Three years of gas production data and downhole gauge data was available for this field.

The initial simulation run was close to the observed data. However, the observed data suggested more pressure support from reservoir is required for the later production period. Well A water sample analysis report also showed a small amount of formation water production which should also be matched by the dynamic model. 
430 In order to achieve a more representative dynamic model, the following history matching parameters for Well A were considered:

- Extension of the more permeable region in the shallower layers as observed in the appraisal well of the field

- Thickness of the more permeable region

- Connection of the more permeable region to the hydraulic fracture zones 4 and 5 to match higher gas production contribution of these zones based on the observed PLT results

- Permeability ( $\mathrm{Y}$ and $\mathrm{Z}$ direction) of global cells around the hydraulic fracture zone 4 to create a higher perm connection to lower layers and also along the maximum horizontal stress. This allows a flow path for water production by representation of vertical open natural fractures which most likely are oriented in the maximum horizontal stress.

Using the above history matching parameters, the dynamic model was tuned and a match of gas production rate, bottomhole pressure, production contribution of each zone and water production rate was achieved. Figure 9 shows Well A along with five hydraulic fractures and water saturation increase in Zone 4 due to its connection to natural fractures. The hydraulic fractures connect to an extensive higher permeable region and natural fracture network, a $150 \mathrm{mD}$ high-permeability region is applied in four sub-layers connected to zones 4 and 5 up to a distance of $200 \mathrm{~m}$ around Well A. This area is illustrated in Figure 9 (the cells with green colour). 


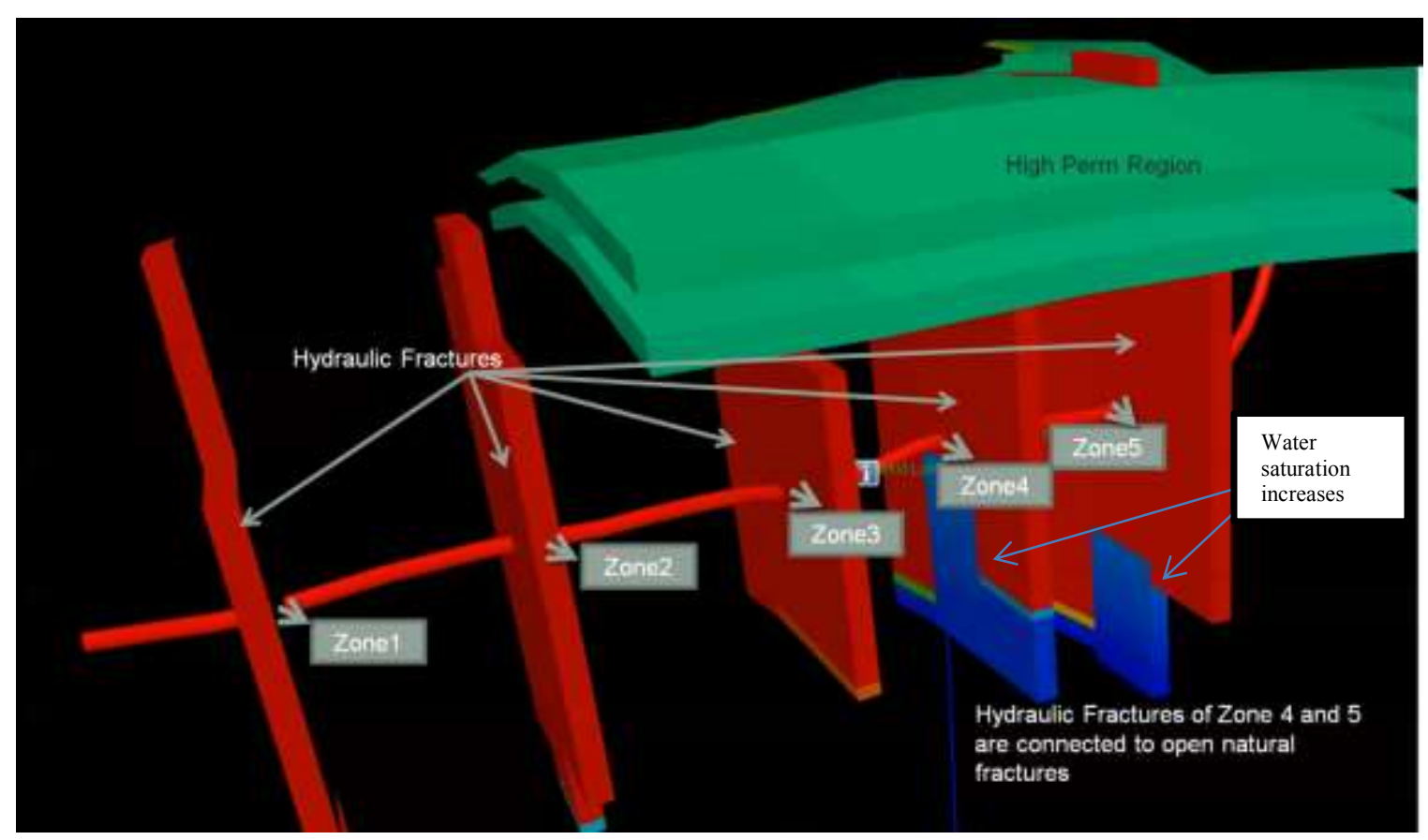

Figure 9. Water saturation on hydraulic fractures of Well A after history matching

\subsection{Validation of Proposed Technique using Actual Data}

451 In order to validate the dynamic model, pressure was predicted prior to the next summer shut down.

452 Shut-in pressure data analysis is widely used in reservoir engineering to describe the production 453 mechanism not only in the close proximity of the well but also in distances further away from the 454 wellbore. The pressure difference and Bourdet derivative on a log-log plot is one of the key diagnostic 455 plots in such an analysis. Matching these plots can demonstrate the accuracy of the model and it is 456 ideal to validate the dynamic model. Therefore a simulation of shut-in build up data was performed 457 during the summer shut down that lasted around three weeks (Figure 10). Comparing the simulation 458 data to real observed data in Well A, a reasonable match was found, where the bilinear flow regime 459 represent the finite conductivity fractures ( $1 / 4$ slope), followed by a transition to a compound linear 460 flow (1/2 slope). 
461 The dynamic model is not supposed to match the early time data due to the effects of wellbore storage 462 however; it should match the pressure differences in the middle to late time regions and ideally the 463 Bourdet derivative. Figure 10 illustrates such a match, which is an evidence for validation of the model.

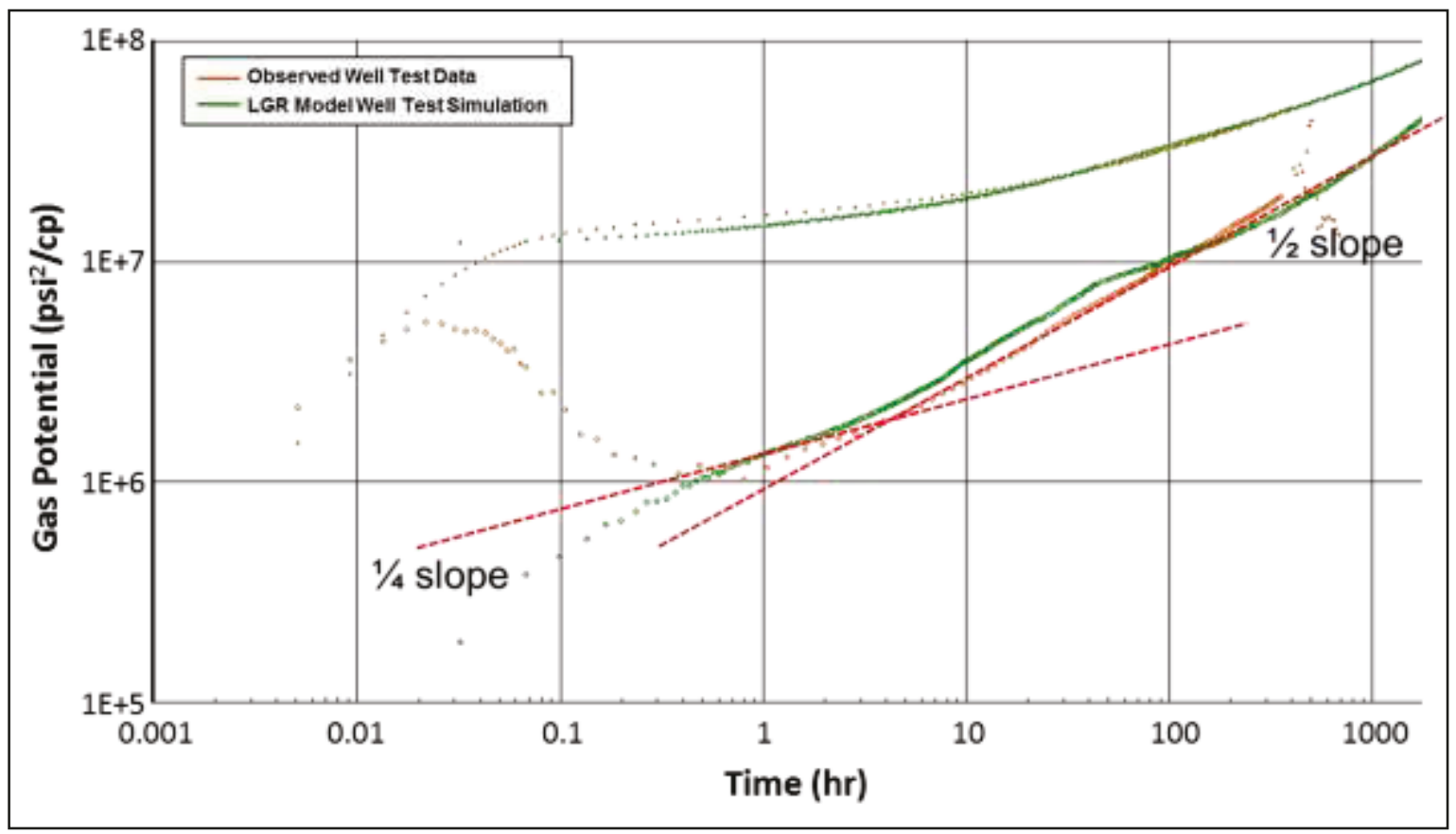

465 Figure 10. Pressure derivative of the LGR model prediction versus observed shut in data for Well A 


\section{Conclusions}

- Different sources of information and analysis such as well test interpretation, net pressure study, fracture production data, fracture conductivity performance versus effective stress and reservoir dynamic modelling are discussed. The technical gap in data integration was identified and WTA/NPM technique is proposed as a solution.

- WTA/NPM technique integrates outcomes of well test interpretation and net pressure analysis in order to establish a quantitative diagnostic parameter for heterogeneity evaluation. This parameter is also used for scaling the NPM fracture conductivity to better represent the fractured well performance behaviour. The dynamic model initialised using such scaled fracture conductivity is more reliable.

- The heterogeneity impact factor (HIF) defined in this study represents a quantified value for expected performance of the hydraulic fracturing on each well. This quantified value represents the contribution of heterogeneity and creates a basis for comparing the wells of the same field with each other. It can also exhibit the impact of heterogeneity between different fields.

- Quantification of heterogeneity impact as a value is important as this value can be used for prediction of well production. This is by integrating tools of production simulation with HIF. HIF can also be used to filter the higher performance wells versus the other wells, purely due to heterogeneity of the area. This can help to analyse the patterns across different wells of the field for drilling targets of the next phases of field development.

- As the successful application of the proposed method has been confirmed by the geological and drilling evidences of encountering zones of natural fractures or highpermeability streaks, HIF analysis can prove valuable in gaining insight to the degree of such zonal heterogeneities which might be expected in other parts of the field in 
case of the absence of enough geological or drilling information. In this sense, HIF analysis, once performed for enough number of wells in a field, could serve as powerful guide in better realising (or at least expecting) the reservoir heterogeneity by considering the HIF range of the wells in different locations of the field.

- HIF can also be used in uncertainty analysis of well production predictions as it gives a range of possible outcomes and, by linking to Decline curves analysis, it can generate hundreds of scenarios in few minutes. This is also another area of future work for the researchers.

- The proposed technique is applied on real field data and the results are presented which shows the robustness of the technique. As an evidence for the dynamic model validation, the prediction of the model is compared with a future 3-week shut-in pressure. The build-up pressure response and its derivative displayed an excellent match between the simulated and observed results.

- This study demonstrates a practical integrated approach towards modelling and evaluation of hydraulic fracture performance in heterogeneous reservoirs.

\section{Nomenclature}

$\begin{array}{ll}\mathrm{C}_{\mathrm{fD}} & \text { Dimensionless Fracture conductivity } \\ \text { DDA } & \text { Discontinuous Deformation Analysis } \\ \mathrm{DEM} & \text { Distinct Element Model (DEM) } \\ \mathrm{FC} & \text { Finite Conductivity } \\ \mathrm{F}_{\mathrm{C}} & \text { Fracture conductivity } \\ \mathrm{HIF} & \text { Heterogeneity Impact Factor } \\ \mathrm{k} & \text { Permeability } \\ \mathrm{K}_{\mathrm{f} \cdot \mathrm{W}} & \text { Connectivity of hydraulic fracture } \\ \text { LGR } & \text { Local grid refinement } \\ \text { LWD } & \text { logging-while-drilling } \\ \text { MD } & \text { Mesured depth } \\ \text { MMSFD } & \text { Million standard cubic feet } \\ \text { NPM } & \text { Net pressure match } \\ \text { PKN } & \text { Perkins-Kern-Nordgren theory }\end{array}$




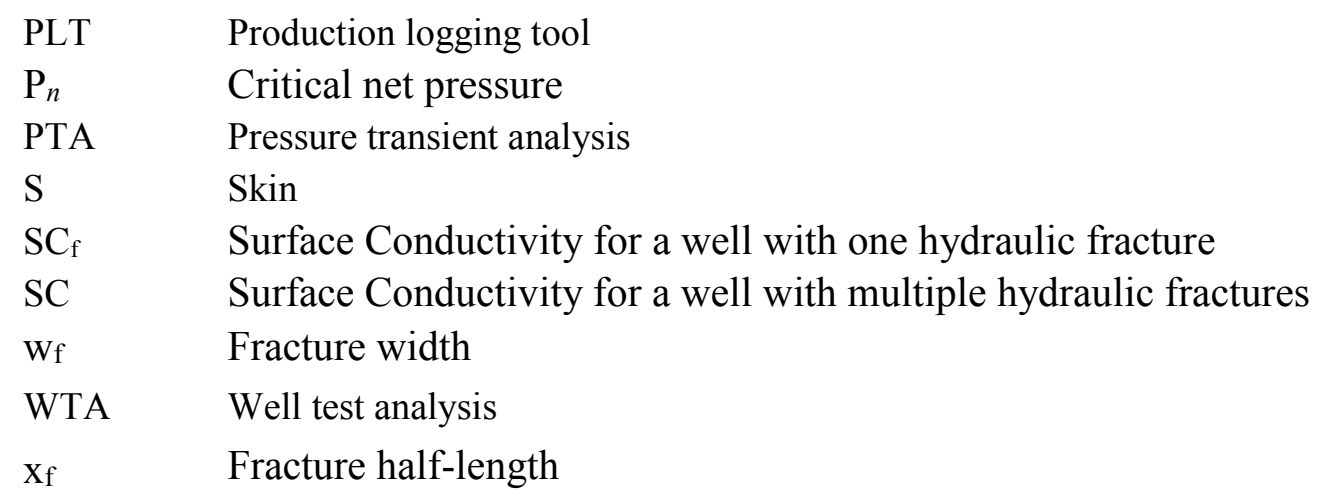

\section{Acknowledgment}

The authors would like to thank E.ON E\&P UK, Dana Petroleum Plc and Bayerngas

UK Ltd for providing the data and their permission to present and publish this material.

Our appreciation goes to Wei-Cher Feng, Paul Arkley, Stephen Hart, Stewart

Brotherton, Alex Kay, Aliona Kubyshkina, Azra Kovac, Helene Nicole, Terje

Rudshaug, David Torr, Terry Wells, Mike Almeida, Paul Jeffs and Basil Al-Shamma

for their useful insights and discussions.

\section{References}

1. Al-Zarouni, A. \& Ghedan, S., 2012. Paving the Road for the First Hydraulic Fracturing in Tight Gas Reservoirs in Offshore Abu Dhabi. SPE152713.

2. Antoci, J. \& Anaya, L., 2001. First Massive Hydraulic Fracturing Treatment in Argentina. SPE69581.

3. Bennett, C., Reynolds, A., Raghavan, R. \& Elbel, J., 1986. Performance of FiniteConductivity, Vertically Fractured Wells in Single-Layer Reservoirs. SPE11029.

4. Clarkson, C.R., 2013. Production data analysis of unconventional gas wells: Review of theory and best practices. Int. J. of Coal Geology 109-110, 101-146.

5. El-Ahmady, M. \& Wattenbarger, R., 2004. Coarse Scale Simulation in Tight Gas Reservoirs. 2004-181 PETSOC.

6. Economides, M., Oligney, R. \& Valko, P., 2002. Unified Fracture Design. Alvin(TX): Olsa Press. 
7. Hamidi, F., Mortazavi, A., 2014. A new three-dimensional approach to numerically model hydraulic fracturing process. Journal of Petroleum Science and Engineering, Volume 124, Pages 451-467.

8. Hegre, T., 1996. Hydraulically Fractured Horizontal Well Simulation. SPE35506.

9. Huang, K., Ghassemi, A., 2012. Modeling 3D Hydraulic Fracture Propagation and Thermal Fracturing Using Virtual Multidimensional Internal Bonds, Proceedings, Thirty-Sixth Workshop on Geothermal Reservoir Engineering Stanford University, Stanford, California, January 30 - February 2, 2012.

10. Iwere, F., Moreno, J., Apaydin, O., Delaney, J., Thrush, P. \& Gwaltney, J, 2004. Numerical Simulation of Thick, Tight Fluvial Sand. SPE90630.

11. Mirzaei-Paiaman A., The Severe Loss of Well Productivity in an Iranian Gas Condensate Carbonate Reservoir: Problem Identification and Remedy, Energy Sources, Part A: Recovery, Utilization, and Environmental Effects, Vol. 35, Issue 19.

12. Nadimi, S., Miscovic, I., McLennan J., 2016. A 3D peridynamic simulation of hydraulic fracture process in a heterogeneous medium. Journal of Petroleum Science and Engineering, Volume 145, Pages 444-452.

13. Nordgren, R.P., 1972. Propagation of a Vertical Hydraulic Fracture. SPE-3009-PA.

14. Parvizi, H., Rezaei-Gomari, S., Nabhani, F. \& Feng, W., 2015a. Hydraulic Fracturing Performance Evaluation in Tight Sand Gas Reservoir with High Perm Streaks and Natural Fractures. SPE174338.

15. Parvizi, H., Rezaei-Gomari, S., Nabhani, F., Dastkhan, Z. \& Turner, A., 2015b. A Practical Workflow for Offshore Hydraulic Fracturing Modelling: Focusing on Southern North Sea. SPE174339.

16. Perkins, T.K. and Kern, L.R., 1961. Widths of Hydraulic Fractures. J. Pet. Tech. 937-949; Trans., AIME, 222.

17. Shaoul, J., Ross, M., Spitzer, W., Wheaton, S., Mayland, P. \& Singh, A., 2007. Massive Hydraulic Fracturing Unlocks Deep Tight Gas Reserves in India. SPE107337.

18. Schulte, W., 1986. Production From a Fractured Well With Well Inflow Limited to Part of the Fracture Height. SPE12882. 
19. Sesetty V., Ghassemi, A., 2012. Modeling and analysis of stimulation for fracture network generation. In: PaperSGP-TR-194 presented at Thirty-Seventh Work-shop on Geothermal Reservoir Engineering Stanford University, Stanford, California, January30-February 1.

20. Sobhaniaragh, B., Mansur, W. J., Peters, F. C., 2016. Three-dimensional investigation of multiple stage hydraulic fracturing in unconventional reservoirs. Journal of Petroleum Science and Engineering, Volume 146, Pages 1063-1078.

21. Sousa, J. L., Carter, B. J., Ingraffea, A. R., 1993. Numerical simulation of 3D hydraulic fracture using Newtonian and power-law fluids. International Journal of Rock Mechanics and Mining Sciences \& Geomechanics Abstracts, Volume 30, Issue 7, Pages 1265-1271.

22. Vos, B., Shaoul, J. \& De Koning, K., 2009. Southern North Sea Tight-Gas Field Development Planning using Hydraulic Fracturing. SPE121680.

23. Wang, H. Y., 2015. Numerical modeling of non-planar hydraulic fracture propagation in brittle and ductile rocks using XFEM with cohesive zone method. Journal of Petroleum Science and Engineering, Volume 135, Pages 127-140.

24. Warpinski, N. R., Moschovidis, Z. A., Parker, C. D., Abou-Sayed, I. S. 1994. Comparison Study of Hydraulic Fracturing Models-Test Case: GRI Staged Field Experiment No. 3 (includes associated paper 28158). SPE-25890-PA. doi:10.2118/25890-PA.

25. Zhang, X., Jeffrey, R.G., Thiercelin, M., 2007. Deflection and propagation of fluid driven fractures at frictional bedding interfaces: A numerical investigation. Journal of Structural Geology, Volume 29, Issue 3, Pages 396-410.

26. Zhang, Z., Li, X., Yuan, W., He, J., Li, G., Wu, Y., 2015. Numerical Analysis on the Optimization of Hydraulic Fracture Networks, Energies, 8(10), 12061-12079; doi:10.3390/en81012061.

27. Zhang, Z., Peng, S., Ghassemi, A., Ge, X., 2016. Simulation of complex hydraulic fracture generation in reservoir stimulation. Journal of Petroleum Science and Engineering, Volume 146, Pages 272-285.

28. Zhao, X. \& Young, R., 2009. Three-dimensional Dynamic Distinct Element Modelling Applied to Laboratory Simulation of Hydraulic Fracturing in Naturally Fractured Reservoirs. 2009-2697 SEG. 


\section{Appendix A}

Fracture average width by net pressure match analysis (based on 24 hydraulic fracture jobs of a Southern North Sea field)

\begin{tabular}{|c|c|c|c|c|c|c|c|c|c|}
\hline $\begin{array}{c}\text { Wel } \\
1\end{array}$ & $\begin{array}{l}\text { Fractur } \\
\text { e width } \\
\text { (in) }\end{array}$ & Well & $\begin{array}{l}\text { Fracture } \\
\text { width } \\
\text { (in) }\end{array}$ & Well & $\begin{array}{c}\text { Fracture } \\
\text { width } \\
\text { (in) }\end{array}$ & Well & $\begin{array}{c}\text { Fracture } \\
\text { width } \\
\text { (in) }\end{array}$ & Well & $\begin{array}{c}\text { Fracture } \\
\text { width } \\
\text { (in) }\end{array}$ \\
\hline \multirow{5}{*}{ A } & 0.165 & \multirow{5}{*}{ B } & 0.067 & \multirow{5}{*}{$\mathrm{C}$} & 0.029 & \multirow{5}{*}{$\mathrm{D}$} & 0.512 & \multirow{5}{*}{$\mathrm{E}$} & 0.37 \\
\hline & 0.371 & & 0.053 & & 0.036 & & 0.188 & & 0.247 \\
\hline & 0.204 & & 0.375 & & 0.25 & & 0.166 & & 0.364 \\
\hline & 0.318 & & 0.298 & & 0.104 & & 0.106 & & 0.208 \\
\hline & 0.292 & & 0.158 & & 0.148 & & - & & 0.235 \\
\hline
\end{tabular}

